\title{
BMJ Open Experiences of Australian men diagnosed with advanced prostate cancer: a qualitative study
}

\author{
Suzanne K Chambers, ${ }^{1,2,3,4,5,6}$ Melissa K Hyde, , ${ }^{1,2}$ Kirstyn Laurie, ${ }^{1,2}$ Melissa Legg, ${ }^{1,2}$ \\ Mark Frydenberg, ${ }^{3,7,8}$ lan D Davis,,$^{3,9}$ Anthony Lowe, ${ }^{1,3,4}$ Jeff Dunn ${ }^{1,2,3,5}$
}

To cite: Chambers SK, Hyde MK Laurie $\mathrm{K}$, et al. Experiences of Australian men diagnosed with advanced prostate cancer: a qualitative study. BMJ Open 2018;8:e019917. doi:10.1136/ bmjopen-2017-019917

- Prepublication history for this paper is available online To view these files, please visit the journal online (http://dx.doi org/10.1136/bmjopen-2017019917).

Received 7 October 2017 Revised 19 January 2018 Accepted 26 January 2018

Check for updates

${ }^{1}$ Menzies Health Institute Queensland, Griffith University, Brisbane, Queensland, Australia ${ }^{2}$ Cancer Research Centre, Cancer Council Queensland, Brisbane, Queensland, Australia ${ }^{3}$ Australian and New Zealand Urogenital and Prostate (ANZUP) Cancer Trials Group, Sydney, New South Wales, Australia ${ }^{4}$ Prostate Cancer Foundation of Australia, Sydney, New South Wales, Australia

${ }^{5}$ Institute for Resilient Regions, University of Southern Queensland, Toowoomba, Queensland, Australia

${ }^{6}$ Health \& Wellness Institute, Edith Cowan University, Perth, Western Australia, Australia ${ }^{7}$ Department of Urology, Monash Health, Melbourne, Victoria,

Australia

${ }^{8}$ Department of Surgery, Faculty of Medicine, Monash University, Melbourne, Victoria, Australia

${ }^{9}$ Eastern Health Clinical School, Monash University, Melbourne, Victoria, Australia

\section{Correspondence to}

Professor Suzanne K Chambers; suzanne.chambers@griffith. edu.au

\section{ABSTRACT}

Objective To explore men's lived experience of advanced prostate cancer (PCa) and preferences for support. Design Cross-sectional qualitative study applying openended surveys and interviews conducted between June and November 2016. Interviews audio-recorded and transcribed verbatim and analysed from an interpretive phenomenological perspective.

Setting Australia, nation-wide.

Participants 39 men diagnosed with advanced PCa (metastatic or castration-resistant biochemical progression) were surveyed with 28 men subsequently completing a semistructured in depth telephone interview. Results Thematic analysis of interviews identified two organising themes: lived experience and supportive care. Lived experience included six superordinate themes: regret about late diagnosis and treatment decisions, being discounted in the health system, fear/uncertainty about the future, acceptance of their situation, masculinity and treatment effects. Supportive care included five superordinate themes: communication, care coordination, accessible care, shared experience/peer support and involvement of their partner/family.

Conclusions Life course and the health and social context of PCa influence men's experiences of advanced disease. Multimodal interventions integrating peer support and specialist nurses are needed that more closely articulate with men's expressed needs.

\section{INTRODUCTION}

Prostate cancer (PCa) is the second most common cancer in men with the highest incidence in Australia/New Zealand and North America. ${ }^{1}$ Most men present with localised disease or disease with regional lymph nodes spread with the relative 5-year survival rate for these men exceeding $95 \% .^{23}$ However, one in five will progress to metastatic disease. ${ }^{4}$ Approximately $5 \%$ of men are diagnosed with metastatic disease and the relative 5 -year survival rate for these men is only $30 \% .^{35}$ The mainstay treatment for advanced PCa is androgen deprivation therapy (ADT) that typically is followed by progression to metastatic castration-resistant PCa. $^{6}$ Once this occurs, median

\section{Strengths and limitations of this study}

- Extends previous research in men with advanced prostate cancer to describing how masculinities, life course and the broader social and public health context influence support needs.

- Robust and transparent study method and the application of a phenomenological approach.

- Valid and reliable and transferable within the Australian setting.

- Cross-sectional design is a study limitation.

survival is less than 2 years, ${ }^{7}$ although recent therapeutic advancements such as abiraterone acetate and enzalutamide have shown potential for further slowing disease progression $^{8}$ with median survival up to 3 years. ${ }^{6}$ The STAMPEDE $^{9}$ and LATITUDE $^{10}$ trials demonstrated a survival advantage for the combined use of abiraterone with commencement of ADT; however, this was offset by earlier and more prolonged androgen suppression and a higher risk of grade $3-5$ adverse events.

Hence, while new treatments for advanced PCa prolong life, this means men are living longer with the effects of treatment and disease progression including deteriorating bone health, pain, hot flushes, loss of libido, erectile dysfunction, increased fat mass, sarcopenia, fatigue and cognitive decline. ${ }^{6} 1112$ Men with advanced PCa have poorer quality of life, higher levels of psychological distress, increased suicide risk and more unmet supportive care needs compared with men with localised disease. ${ }^{13-16}$ Approximately one in four experience regret about treatment decisions and this is associated with poorer quality of life and increased distress. ${ }^{17}$ In sum, the burden associated with advanced $\mathrm{PCa}$ is substantial and further evolving as new treatments emerge. 
To date there is scant psychosocial or supportive care intervention research directly targeting men with advanced PCa and the one randomised trial of scale completed by our team failed to prove effectiveness. ${ }^{15} 18$ Researchers in Canada and Scotland have previously highlighted the persisting support services gap for men with advanced PCa and suggested more qualitative research elucidating men's experiences is needed if we are to develop effective supportive care interventions. ${ }^{19}{ }^{20}$ Carter et al in 2011 explored the supportive care needs of men with advanced PCa and concluded that functional issues, information needs and emotional distress were the three domains of need that needed to be addressed. ${ }^{19}$ More recently, Paterson et al (2017) interviewed eight men with advanced PCa describing a broader range of challenges extending to interpersonal and intimacy needs. ${ }^{20}$ Both studies emphasised the gap in informational support for these men; however, neither deeply explored issues related to masculinities nor the broader social and public health context in which this illness experience is nested. ${ }^{21-23}$ We sought to extend this previous work more specifically connecting our enquiry between men's challenges in facing advanced PCa and their preferences for support within their social context. Accordingly, we applied an interpretative phenomenological approach to describe the lived experience of men with advanced PCa (proven metastatic or castration-resistant biochemical regression) and their supportive care preferences.

\section{METHOD}

\section{Study design}

This study applied a cross-sectional qualitative design. In a first step, participants reflected on their experience with advanced $\mathrm{PCa}$ via a mail administered open-ended survey. These responses provided a context to inform development of a protocol to guide subsequent semistructured in-depth telephone interviews. Consistent with the study aim to describe men's lived experiences in the context of advanced PCa, we adopted an interpretative phenomenological perspective. ${ }^{2425}$

\section{Participants and recruitment}

Participants were recruited from an existing patient cohort. ${ }^{15}$ In brief, this was a cohort drawn from treatment centres across Australia with participants from five Australian states. In June 2016, we contacted men who had not withdrawn from the cohort and were not to our knowledge deceased and had consented to future contact $(n=141)$. In all, 39 men returned the survey (28\% response) and of these 28 were available for telephone interview between September 2016 and November 2016 (72\% response). Similar to the cohort from which participants were drawn, the mean age of participants was 72.7 years $(\mathrm{SD}=8.5$; range 58.2-94.6) with the majority born in Australia (75\%), married $(86 \%)$ and retired $(79 \%)$; men resided across four
Table 1 Sociodemographic characteristics and treatment information for participants completing an open-ended survey and telephone interview

\begin{tabular}{llll}
\hline & & $\begin{array}{l}\text { Time since } \\
\text { diagnosis }\end{array}$ & $\begin{array}{l}\text { Received } \\
\text { hormone } \\
\text { treatment } \\
\text { (Years) }\end{array}$ \\
\hline Participant ID
\end{tabular}

$\mathrm{N}$, no; NR, not reported; Y, yes.

Australian states. With regard to educational level, 7 men had a college degree, 15 had a trade or technical certificate/diploma, 2 had completed senior high school and 4 had completed junior high school. Mean time since diagnosis was 7.7 years $(\mathrm{SD}=5.0$; range 2.1-22.8). Most men were treated with ADT (88\%), $73 \%$ radiation therapy and $62 \%$ prostatectomy. Men who did not participate were either too unwell $(n=4)$, had a hearing impairment $(n=1)$ or did not consent $(n=6)$. Table 1 reports sociodemographic characteristics and treatment information for each interview participant.

\section{Data collection}

Men responded to four questions in the survey about their PCa-related concerns: assistance or support accessed for 
Table 2 Interview questions

\begin{tabular}{|c|c|}
\hline Focus area & Question \\
\hline Health system & $\begin{array}{l}\text { Thinking about your medical treatment, what changes do you feel would make medical services better meet the } \\
\text { needs of men with advanced prostate cancer? }\end{array}$ \\
\hline $\begin{array}{l}\text { Supportive } \\
\text { care needs }\end{array}$ & $\begin{array}{l}\text { Thinking about the future and the worries that face a man with prostate cancer that has advanced or recurred, } \\
\text { what sort of support would help most? }\end{array}$ \\
\hline $\begin{array}{l}\text { Preferred } \\
\text { approaches }\end{array}$ & $\begin{array}{l}\text { In developing services to help men cope or manage better with advanced prostate cancer, can you describe } \\
\text { support approaches or ways of helping that would be more attractive to men? }\end{array}$ \\
\hline Other & $\begin{array}{l}\text { Thinking about what we have spoken about today, is there anything else we haven't covered that you think is } \\
\text { important to supporting men with advanced prostate cancer? }\end{array}$ \\
\hline
\end{tabular}

these concerns and from whom, other support needed and preferences for support for men. Thematic analysis $^{26}$ of responses (MKH, KL, SKC) indicated four areas that were challenging for men and in which they lacked support: information, medical care, side-effects and the future. Three experienced female interviewers in a research fellow or research assistant position with postgraduate training in the behavioural sciences (ML, KL, EE) conducted telephone interviews to further explore the key areas identified. Interviews were on average $62.1 \mathrm{~min}$ in length $(\mathrm{SD}=19.2$; range=29.2-111.9 $\mathrm{min})$. Member checking occurred at the beginning of each interview during which the interviewer asked participants to comment on the accuracy of researcher interpretation of survey results and gave participants the opportunity to add anything they thought had been missed. Interview questions (table 2) explored in greater depth the concerns previously identified in men's survey responses: health system concerns, supportive care needs, barriers to support and preferred approaches. Participants were invited to discuss other aspects of their experience that they considered were important. Interviews were audio-recorded and transcribed verbatim.

\section{Data analysis}

Interview transcripts were analysed using thematic analysis. $^{2627}$ Themes were derived inductively from the data by reading and re-reading the interview narratives and from this developing an understanding of men's lived experience through their words. Coders had social and behavioural science (SKC, MKH, JD, KL) and nursing (SKC) backgrounds with a wide range of experience from 2 to 20 years working in psycho-oncology and PCa research and included male and female researchers. Transcripts were coded iteratively with constant comparison between the codes generated and the data to ensure that consistent and diverging responses were incorporated. Two research team members independently coded one-third of the transcripts and generated a preliminary coding scheme (MKH, KL). This coding scheme was further refined with a third (SKC) and fourth (JD) research team member. Once all interview transcripts were included, the coding scheme was further reviewed and agreed on by all coders. Exemplar responses were identified across transcripts to illustrate and confirm labelling of themes. Reporting of data is consistent with consolidated criteria for reporting

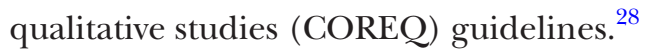

\section{RESULTS}

Thematic analysis identified two organising themes: lived experience and supportive care. The first organising theme reflected men's lived experience with advanced PCa and within this six superordinate themes. The second organising theme captured elements of supportive care that men found challenging and their preferences for how care should be delivered with five superordinate themes. Figure 1 depicts the coding structure. Tables 3 and 4 present illustrative quotes for each superordinate theme.

\section{Lived experience}

Men's lived experience with advanced PCa included six superordinate themes: regret about late diagnosis and treatment decisions, being discounted in the health system, fear/uncertainty about the future, acceptance of their situation, masculinity and treatment effects (table 3).

\section{Regret about late diagnosis and treatment decisions}

Most men described feeling regret about late diagnosis or treatment and this was commonly attributed to delays by clinicians. Many men perceived these delays were caused by general practitioners and/or specialists who would not perform digital rectal examinations or prostate-specific antigen (PSA) testing, did not detect PCa until it was well advanced despite regular testing and did not refer patients for further treatment or testing in a timely manner despite men's requests for them to do so. From this, some men were left with a distrust of the medical 


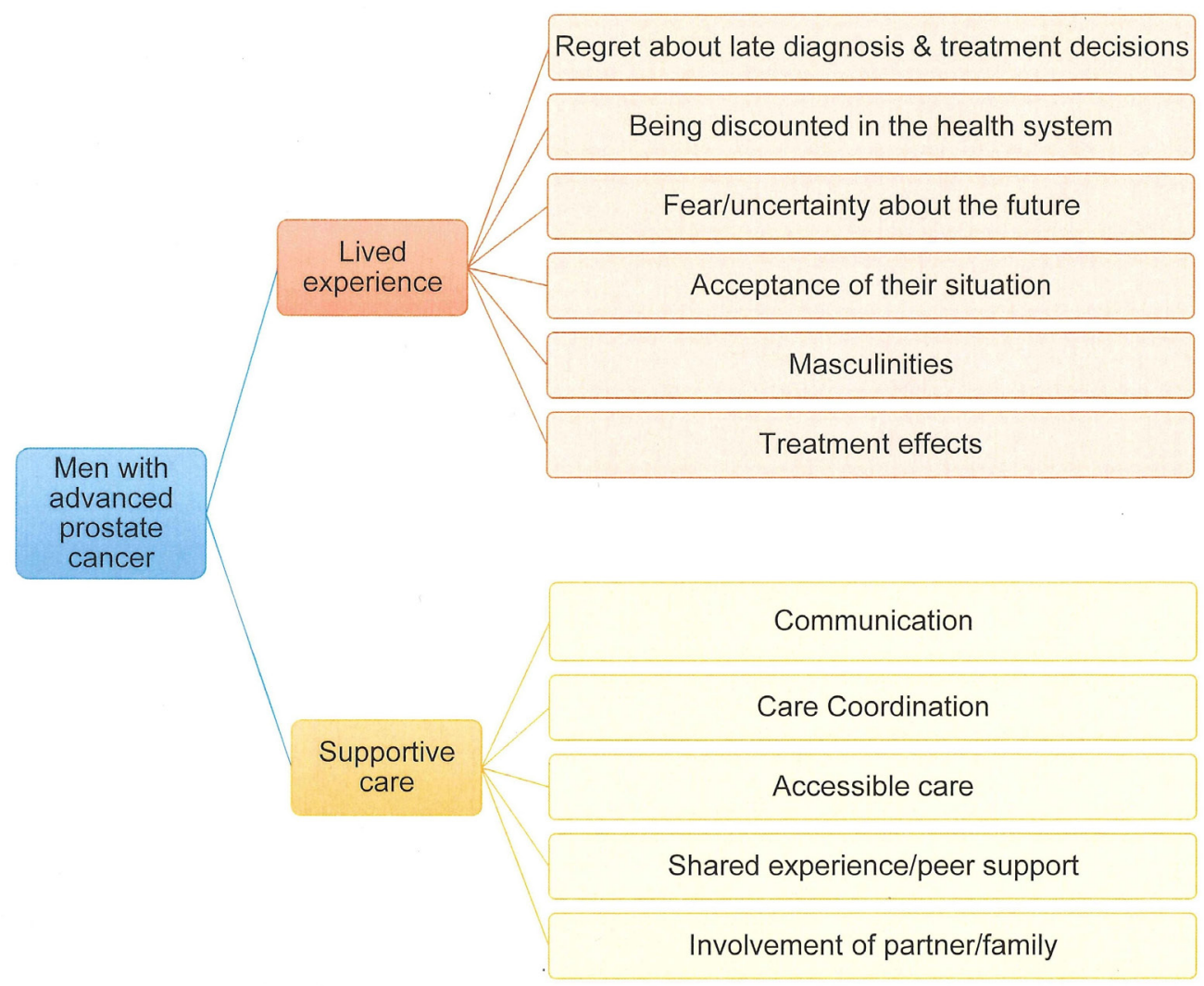

Figure 1 Coding structure derived from thematic analysis.

profession. Many men also discussed regretting their treatment choices and not having had a second opinion so that they felt more adequately informed and clearly understood the outcomes of treatment, including side effects and how these could be managed.

\section{Being discounted in the health system}

In their interactions with clinicians, most men described their concerns, needs and autonomy as discounted or ignored. Many men felt devalued and believed they were somehow less important in the broader health system. In their experience, PCa was the 'poor cousin' of breast cancer in terms of funding, research focus and controversy over the value of PSA testing and less effort by the government and non-profits to promote awareness of PCa. Some men also considered that they and their cancer were less important due to their older age and community attitudes where PCa is considered a cancer that may not lead to death.

Fear/uncertainty about the future

An uncertain future was discussed in terms of most men needing to make 'the unknowable' a known entity by understanding how much time they may have left to live, what lies ahead for disease progression and quality of life, potential treatment options and next steps for support when all treatment options had been exhausted. This information was critical to their ability to feel more in control and to prepare for the future both psychologically and practically while they were well enough to do so. By contrast, some men discussed not wanting to know what the future held in order to focus on their day-to-day life.

\section{Acceptance}

Many men used their age as a frame to accept physical changes and the threat to their mortality. Other approaches adopted by many men to reach acceptance were focusing on 'getting on with it', and viewing ongoing physical effects of the disease or its treatment as part of life, an inevitable outcome of treatment or disease progression and as a favourable alternative to death. Regarding sexuality, some men found changes in their physical capacity to have sex an ongoing cause of distress. Other men shifted their focus to other aspects of their relationships (eg, expressing intimacy in ways 


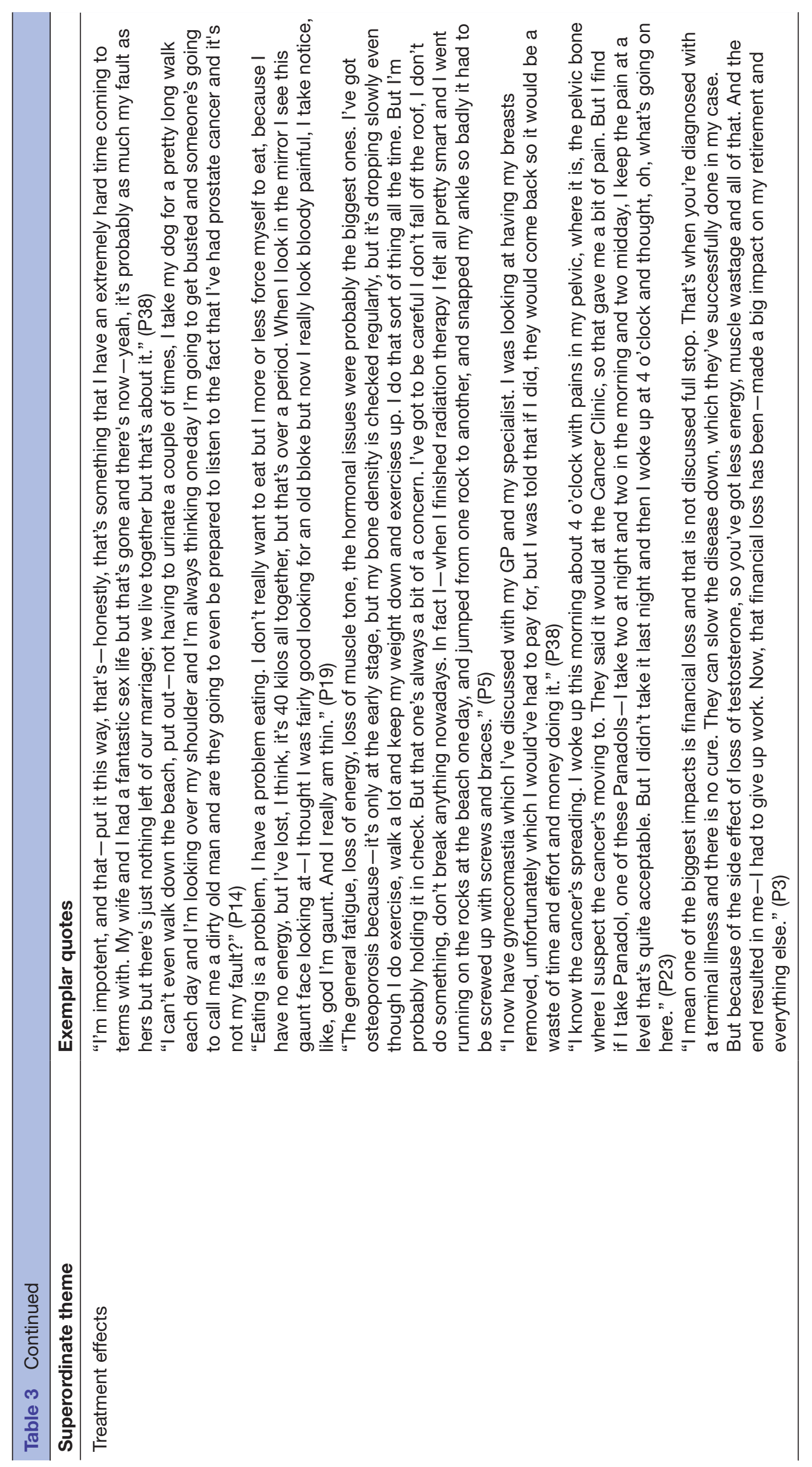




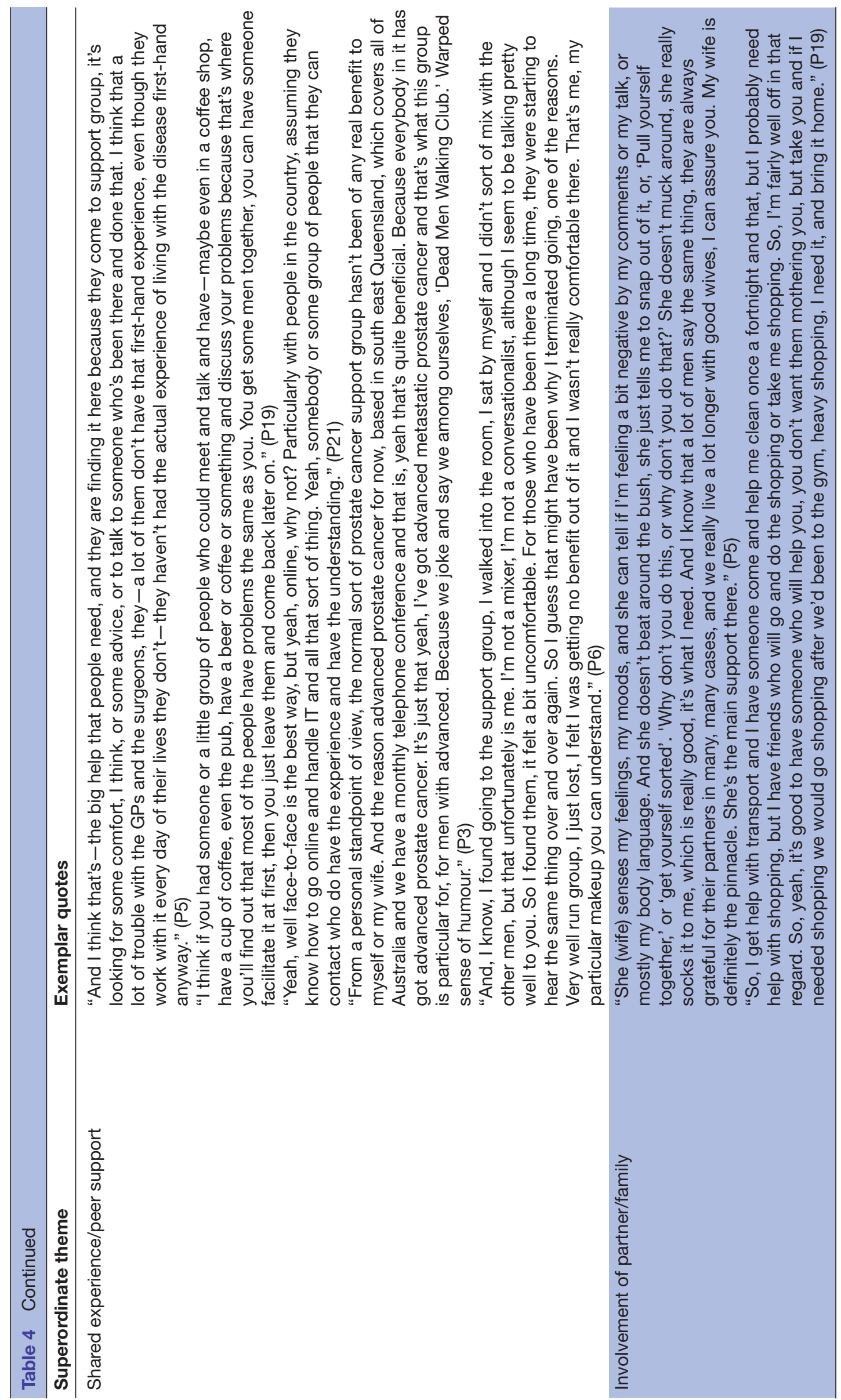


that do not require an erection) as a way to accept their situation.

\section{Masculinities}

Male values and masculinities were discussed as central to most men's experience of PCa, support and coping. Many men believed that as a group they do not look after themselves, go to the doctor, ask for help or talk about their problems by comparison to women and have a different view on their health, are less prepared to discuss their health and gave health less attention. This reluctance to seek help or support or talk about their problems was ascribed to male values around being strong, capable, independent/autonomous or stoic. Many men used avoidance as a coping approach by avoiding thinking or talking about their situation and covering up or ignoring side-effects or a need for support. Some men expressed concerns that there would be negative consequences socially or in their employment if others knew about their cancer. Privacy and being embarrassed talking about personal issues were also raised by many men. Viewing sexuality and sexual function as important to their identity as a man meant that some men were deeply troubled by changes in sexuality and believed that their relationship with their partner now would be negatively impacted or that it would no longer be possible for them to start new relationships with women.

In their perceived role as 'the provider' and 'the protector', some men expected to give help rather than receive it. Some men tried to protect their wives or their family by not talking about their problems and thus avoid worrying them. Many also adopted approaches to promote adjustment including being optimistic and 'getting on with it', taking responsibility for their health and well-being (eg, remaining physically active) as well as an action-oriented approaches in which they identified and solved problems directly or sought help or support. In using these approaches, men saw themselves as uninhibited by masculine norms, which typically constrain help seeking. Many men devalued 'talk' as a way to obtain support and viewed psychologists as not able to provide the solutions they needed, also describing unfavourable attitudes towards support groups as an opportunity for self-pity or drama.

\section{Treatment effects}

All men discussed the effects of advanced PCa and its treatment that affected their quality of life, relationships, capacity to do daily tasks and for many men were highly distressing. Prominent among these were physical effects and financial concerns. Physical effects included the inability to obtain an erection, lack of libido, urinary incontinence, changes in appearance and bodily structure including gynecomastia, weight gain, sarcopenia, decreased bone density, fatigue, dizziness, loss of balance, breathlessness, hot flushes, cognitive changes and pain. Some men discussed no longer being well enough to work and that this negatively affected their income and retirement plans.

\section{Supportive care}

The organising theme supportive care included five superordinate themes: communication, care coordination, accessible care, shared experience/peer support and involvement of their partner/family (table 4).

\section{Communication}

Men had mixed experiences in their interactions and communication with health professionals. Four pivotal points in the care trajectory in which effective communication appeared most critical were: diagnosis, deciding on treatment options, treatment effects and symptom management and follow-up care. Many men described being unclear about the specifics of their diagnosis (eg, staging, PSA) whereas, by contrast, some men appreciated the direct and honest approach adopted by their clinicians when communicating about the severity of their disease. When discussing treatment options, men desired more guidance and support in making a treatment decision and for options to be more clearly communicated so that they could better understand long-term treatment effects. Some men were dismayed that their general practitioners (GP) or other health professionals did not seem to have specialised knowledge about PCa. Preferred decision support included clear, unbiased communication about the pros and cons of each treatment option and referral to other sources of information that men could consider in their own time.

Some men described confusion and frustration when they were given a treatment that they needed to self-administer (eg, injections) but were not effectively instructed in how to do this. Men commonly discussed health professionals' communication about treatment side-effects as insufficient (eg, told about effects but not how to deal with them) and selective (eg, told about immediate but not long-term effects) and as a consequence felt unprepared and isolated in their experience. Some men described not being listened to when they raised their concerns or being unable to get clear answers to questions. Some men expressed that it was up to them to find solutions to manage their side-effects because clinicians did not adequately address these.

\section{Care coordination}

For some men, regular ongoing communication with their clinicians was a source of support; however, other men felt out of touch and isolated due to the length of time between each consultation. GPs were important to some men in helping them feel connected with their care team. Most men discussed the need for better coordinated care and information and this was focused on three aspects: communication between health professionals, having a 'middle man' and integrating psychosocial support as part of routine care.

A lack of communication between specialist clinicians regarding treatment and referral was discussed by many men as problematic. Men had mixed views as to who should be the central point of call for information and 
referral. Some men believed this should be their GP; others suggested their urologist or oncologist. Patient advocates or navigators were also discussed by some men as an option to help streamline and clarify the diagnostic and treatment process. Some men discussed PCa nurses as being central to their care. Nurses provided informational, emotional and practical support that clarified men's understanding of their situation, served as an intermediary between the patient or couple and other clinicians and were seen as more likely to refer them to other beneficial services than other healthcare professionals. These men discussed that the best time to be connected with a PCa nurse was at diagnosis with continued access throughout treatment.

Some men identified the need to integrate psychosocial support as part of routine care without relying on men themselves to raise emotional issues with clinicians. Alongside this, some men also discussed the need for routine referral to support groups or information about the existence of local groups and exercise programmes as helpful for weight gain and muscle wastage and managing feelings of loss of masculinity.

\section{Accessible care}

Many men discussed three main barriers to accessible care: geographic location, ill health and financial cost of treatment. Some men experienced difficulty accessing services because they resided in a regional or rural location where services were either not available or required them to travel long distances with resultant cost and inconvenience. Some men had difficulty or were prevented from accessing central or nearby services due to ill health or fatigue; and some men discussed the high financial cost of treatments or drugs to manage side-effects such as erectile dysfunction and uncertainty about how to cover these costs. To overcome accessibility issues, these men suggested use of online or telephone services for those in rural or regional areas or who could not access care due to ill health, lobbying the government to subsidise financial costs of treatment and increasing the availability of home-based medical care or practical assistance services.

\section{Shared experience/peer support}

The opportunity to talk to other men in the same situation was discussed by most men as a source of support that they had, or wished they had, an awareness of and access to. Three aspects of shared experience/peer support: benefits, delivery preferences and barriers were described. Shared experience was highly valued by most men because it allowed them to talk to someone who had been through the same experience, obtain information or advice when weighing up treatment decisions or managing side effects, make positive upward (eg, other men doing well and inspiring hope for recovery) or downward (eg, other men are doing worse so I am ok) comparisons, ${ }^{29}$ gave men a safe and confidential forum to express their concerns and helped men to feel less alone. However, some men did not associate peer support or being connected to support groups with the concept of sharing mutual experiences. Rather discussed it in relation to the naturally occuring companionship with other men from social or sporting clubs or Men's Sheds.

Most men proposed different delivery methods for peer support (eg, face-to-face, telephone or online) to take into account individual differences and need for privacy or anonymity. Both structured (eg, with a facilitator and an agenda) and unstructured (eg, a chat over coffee) methods were acceptable. Some men preferred shared experiences specifically for men with advanced disease on the basis that men with localised disease have different treatments and cancer-related physical effects.

Finally, despite acknowledging the benefits of shared experience, many men also discussed barriers to peer support use. These included feeling uncomfortable to share in a group, the difficulty of sustaining support groups, death of peers and the belief that support groups were focused only on emotional or psychological information.

Involvement of partner/family

In addition to shared experience, most men identified partners and/or family and friends as sources of support that contributed to their emotional and physical wellbeing. For most men, female partners were their main source of emotional and practical support. Many men discussed that partners were impacted by the diagnosis and treatment of PCa and believed it was important to involve and support partners in their care. Some men commented that partners are often the catalyst for their involvement in support groups or seeking out information/support from other sources. Broader family and friends were also discussed by some men as sources of support, often providing practical assistance.

\section{DISCUSSION}

The present study extends previous research about the experience of men with advanced PCa, adding an additional level of description that provides insight into how health context influences men's responses, the influence of life course and ways in which masculinities is expressed in this setting. As in previous research, difficulties with accessible informational support about the disease and its treatment were highly evident. ${ }^{19} 2030$ That these problems persist and are remarkably similar in Canada, ${ }^{19}$ Scotland ${ }^{20}$ and in our Australian data, is striking and suggests that globally there may be a gap in health systems' responses to advanced PCa. PCa survivorship research has to date been underfunded by comparison to breast cancer ${ }^{31}$; a consensus about clinical care for advanced PCa is just now emerging ${ }^{32}$ and the historical and persistent debate about the early detection of $\mathrm{PCa}^{23} 33$ are likely contributors to this. The men's reports in our study of PCa having a less favourable public profile reflect this and show how the broader public health and social context can have a 
profound negative impact on an already difficult cancer experience.

The influence of life course in response to illness in terms of men's age and the expression of masculinities and masculine models of coping strongly emerged in this study and this has implications for the design of care models. ${ }^{34}$ We propose that there is a need to newly conceptualise and then deliver what men actually want, rather than starting from a first principle of revising services already provided that are not meeting men's needs. Men underuse psychosocial support services after cancer compared with women with breast cancer ${ }^{35}$; and previous research has suggested that interventions promoting self-management in men with chronic diseases should include action oriented approaches if they are to be used. ${ }^{36}{ }^{37}$ With regard to providers of support, men in the present study proposed both peer support and nurse specialists as preferred care providers, confirming previous research. ${ }^{38}$

Limitations of this study include the cross-sectional design. Recent qualitative research applying a prospective study design proposed that coping with advanced cancer evolves over time as symptoms progress and fluctuate. ${ }^{39}$ Future research using a prospective case study design will add further depth to our understanding of men's experiences in the face of advancing PCa. As well, the men in our study were not newly diagnosed with advanced disease and so reports of their experience at the time of diagnosis or initial disease progression are retrospective and subject to recall bias. Strengths include a robust and transparent study method and the involvement of men across four Australian states with varied sociodemographic backgrounds such that our data can be considered broadly relevant across the Australian setting. We do note that our participant group was not ethnically diverse and so likely does not represent these experiences, that have been well described elsewhere. ${ }^{40}$

Based on our previous research ${ }^{18} 41$ and the present results we propose five key content elements for inclusion in supportive care interventions with men with advanced PCa: decision support, treatment education with self-management and skills training for symptoms, including exercise prescription, routine screening for psychological distress with referral, psycho-education with tailored distress management strategies, communicating with health professionals. Strategies to integrate peer support within the care team are needed. Finally, the PCa specialist role presents as highly acceptable to men and is ideally placed for supportive care delivery and care coordination. ${ }^{42}$

In conclusion, supportive care services for men with advanced PCa need to be multimodal and take into account the influence of life course on men's illness experience. There is a need for the health system to prioritise research and development in clinical PCa care taking a more holistic approach than currently exists.

Correction notice This article has been corrected since it first published. In the
Abstract, "(metastatic or castration-resistant biochemical regression)" has been corrected to "(metastatic or castration-resistant biochemical progression)".

Acknowledgements We thank Elizabeth Eldridge and Leah Zajdlewicz for research assistance. We gratefully acknowledge the men who generously gave their time for this study.

Contributors SKC, JD and MKH conceived the study, developed the interview protocol, undertook the analyses and interpretation and led manuscript development. KL recruited and interviewed participants, undertook analysis and contributed to writing the manuscript. ML recruited and interviewed participants. MF, IDD and AL contributed to data interpretation. All authors contributed to revisions and approved the final manuscript.

Funding This research received no specific grant from any funding agency in the public, commercial or not-for-profit sectors. IDD is supported by an NHMRC Practitioner Fellowship(APP1102604).

Competing interests None declared.

Patient consent Obtained.

Ethics approval Ethical approval was obtained from the Griffith University Human Research Ethics Committee (Reference number 2016/418).

Provenance and peer review Not commissioned; externally peer reviewed.

Data sharing statement The authors have full control of all primary data and agree to allow the journal to review their data if requested.

Open Access This is an Open Access article distributed in accordance with the Creative Commons Attribution Non Commercial (CC BY-NC 4.0) license, which permits others to distribute, remix, adapt, build upon this work non-commercially, and license their derivative works on different terms, provided the original work is properly cited and the use is non-commercial. See: http://creativecommons.org/ licenses/by-nc/4.0/

(c) Article author(s) (or their employer(s) unless otherwise stated in the text of the article) 2018. All rights reserved. No commercial use is permitted unless otherwise expressly granted.

\section{REFERENCES}

1. Ferlay J, Soerjomataram I, Ervik M, et al. GLOBOCAN 2012 v1. 0, Cancer Incidence and Mortality Worldwide: IARC CancerBase No. 11. Lyon, France: International Agency for Research on Cancer, 2013. globocan. iarc. fr/Default. aspx (accessed 8th Apr 2017).

2. Australian Institute of Health and Welfare. Cancer in Australia 2017. Cancer series no. 101. Cat. No. CAN 100. Canberra, Australia: AlHW, 2017.

3. National Cancer Institute. SEER Cancer stat facts: prostate cancer. Bethesda, MD: National Cancer Institute, 2016. http://seer.cancer. gov/statfacts/html/prost.html (accessed 8th Apr 2017).

4. Luo Q, Yu XQ, Smith DP, et al. A population-based study of progression to metastatic prostate cancer in Australia. Cancer Epidemiol 2015;39:617-22.

5. American Cancer Society. Cancer facts \& figures 2017. Atlanta,GA: American Cancer Society, 2017.

6. Crawford ED, Petrylak D, Sartor O. Navigating the evolving therapeutic landscape in advanced prostate cancer. Urol Oncol 2017;35S:S1-13.

7. Heidenreich A, Bastian PJ, Bellmunt J, et al. Guidelines on prostate cancer 2012: European Association of Urology, 2012.

8. Afshar M, Evison F, James ND, et al. Shifting paradigms in the estimation of survival for castration-resistant prostate cancer: a tertiary academic center experience. Urol Oncol 2015;33:338.e1-7.

9. James ND, de Bono JS, Spears MR, et al. Abiraterone for prostate cancer not previously treated with hormone therapy. N Engl J Med 2017;377:338-51.

10. Fizazi K, Tran N, Fein L, et al. Abiraterone plus Prednisone in Metastatic, Castration-Sensitive Prostate Cancer. N Engl J Med 2017;377:352-60.

11. Gilbert DC, Duong T, Kynaston HG, et al. Quality-of-life outcomes from the Prostate Adenocarcinoma: TransCutaneous Hormones (PATCH) trial evaluating luteinising hormone-releasing hormone agonists versus transdermal oestradiol for androgen suppression in advanced prostate cancer. BJU Int 2017;119:667-75.

12. Resnick MJ, Penson DF. Quality of life with advanced metastatic prostate cancer. Urol Clin North Am 2012;39:505-15.

13. Bill-Axelson A, Garmo H, Lambe M, et al. Suicide risk in men with prostate-specific antigen-detected early prostate cancer: a 
nationwide population-based cohort study from PCBaSe Sweden. Eur Urol 2010;57:390-5.

14. Bloch S, Love A, Macvean M, et al. Psychological adjustment of men with prostate cancer: a review of the literature. Biopsychosoc Med 2007;1:2.

15. Chambers SK, Occhipinti S, Foley E, et al. Mindfulness-based cognitive therapy in advanced prostate cancer: a randomized controlled trial. J Clin Oncol 2017;35:291-7.

16. Eton DT, Lepore SJ. Prostate cancer and health-related quality of life: a review of the literature. Psychooncology 2002;11:307-26.

17. Clark JA, Wray NP, Ashton CM. Living with treatment decisions: regrets and quality of life among men treated for metastatic prostate cancer. J Clin Oncol 2001;19:72-80.

18. Chambers SK, Hyde MK, Smith DP, et al. New challenges in psycho-oncology research III: A systematic review of psychological interventions for prostate cancer survivors and their partners: clinical and research implications. Psychooncology 2017;26:873-913.

19. Carter N, Bryant-Lukosius D, DiCenso A, et al. The supportive care needs of men with advanced prostate cancer. Oncol Nurs Forum 2011;38:189-98.

20. Paterson C, Kata SG, Nandwani G, et al. Unmet supportive care needs of men with locally advanced and metastatic prostate cancer on hormonal treatment. Cancer Nurs 2017:40:497-507.

21. Chambers SK, Hyde MK, Oliffe JL, Zajdlewicz L, et al. Measuring masculinity in the context of chronic disease. Psychol Men Masc 2015;17:228-42.

22. Chambers SK, Chung E, Wittert G, et al. Erectile dysfunction, masculinity, and psychosocial outcomes: a review of the experiences of men after prostate cancer treatment. Transl Androl Urol 2017;6:60-8.

23. Dunn J, Casey C, Sandoe D, et al. Advocacy, support and survivorship in prostate cancer. Eur J Cancer Care 2017;1:e12644.

24. Davidsen AS. Phenomenological approaches in psychology and health sciences. Qual Res Psychol 2013;10:318-39.

25. Lopez KA, Willis DG. Descriptive versus interpretive phenomenology: their contributions to nursing knowledge. Qual Health Res 2004:14:726-35.

26. Braun V, Clarke V. Using thematic analysis in psychology. Qual Res Psychol 2006;3:77-101.

27. Wojnar DM, Swanson KM. Phenomenology: an exploration. J Holist Nurs 2007;25:172-80.

28. Tong A, Sainsbury P, Craig J. Consolidated criteria for reporting qualitative research (COREQ): a 32-item checklist for interviews and focus groups. Int J Qual Health Care 2007;19:349-57.
29. Wood JV. Theory and research concerning social comparisons of personal attributes. Psychol Bull 1989;106:231-48.

30. Jenkins VA, Fallowfield LJ, Jenkins VA. No man's land: information needs and resources of men with metastatic castrate resistant prostate cancer. Support Care Cancer 2016;24:4471-3.

31. AlHW. Cancer in Australia 2010: an overview. Canberra: Australian Institute of Health and Welfare, 2010.

32. Gillessen S, Attard G, Beer TM, et al. Management of patients with advanced prostate cancer: the report of the Advanced Prostate Cancer Consensus Conference APCCC 2017. Eur Urol 2018;73:178-211.

33. Lepor H. Opinion makers: revisiting the USPSTF Decision on PSA Tests - Urologist Herbert Lepor, MD, sets forth 'sensible solution': Medpage Today, 2016.

34. Evans J, Frank B, Oliffe JL, et al. Health, Illness, Men and Masculinities (HIMM): a theoretical framework for understanding men and their health. J Mens health 2011;8:7-15.

35. Forsythe LP, Kent EE, Weaver KE, et al. Receipt of psychosocial care among cancer survivors in the United States. J Clin Oncol 2013;31:1961-9.

36. Galdas PM, Cheater F, Marshall P. Men and health help-seeking behaviour: literature review. J Adv Nurs 2005;49:616-23.

37. Roesch SC, Adams L, Hines A, et al. Coping with prostate cancer: a meta-analytic review. J Behav Med 2005;28:281-93.

38. King AJ, Evans M, Moore TH, et al. Prostate cancer and supportive care: a systematic review and qualitative synthesis of men's experiences and unmet needs. Eur J Cancer Care 2015;24:618-34.

39. Roberts D, Calman L, Large P, et al. A revised model for coping with advanced cancer. Mapping concepts from a longitudinal qualitative study of patients and carers coping with advanced cancer onto Folkman and Greer's theoretical model of appraisal and coping. Psychooncology 2018;27:229-35.

40. Rivas C, Matheson L, Nayoan J, et al. Ethnicity and the prostate cancer experience: a qualitative metasynthesis. Psychooncology 2016;25:1147-56.

41. Zopf EM, Newton RU, Taaffe DR, et al. Associations between aerobic exercise levels and physical and mental health outcomes in men with bone metastatic prostate cancer: a cross-sectional investigation. Eur J Cancer Care 2017;26:e12575.

42. Carter N, Miller PA, Murphy BR, et al. Healthcare providers' perspectives of the supportive care needs of men with advanced prostate cancer. Oncol Nurs Forum 2014;41:421-30. 